\title{
A Questionnaire Case Study to Investigate Public Awareness of Smog Pollution in China's Rural Areas
}

\author{
Li Jiang ${ }^{1,2}$, Erkki Hiltunen ${ }^{2}$, Xianglin $\mathrm{He}^{3}$ and Liandong $\mathrm{Zhu}{ }^{4, *}$ \\ 1 Faculty of Marxism, Huazhong Agricultural University, Wuhan 430070, China; jiangli@mail.hzau.edu.cn \\ 2 Environmental Management Research Group, Vaasa University, Vaasa FI-65101, Finland; \\ erkki.hiltunen@uva.fi \\ 3 Institute for Advanced Humanistic Studies, Hubei University, Wuhan 430062, China; hxl129@163.com \\ 4 Vaasa Energy Institute, FI-65101 Vaasa, Finland \\ * Correspondence: zliand@uva.fi; Tel.: +358-408-480-438
}

Academic Editor: Marc A. Rosen

Received: 29 August 2016; Accepted: 27 October 2016; Published: 31 October 2016

\begin{abstract}
Smog pollution is one of China's most pressing public health issues today and has therefore received significant attention worldwide. Not only cities but also villages in China are suffering from smog pollution, especially since 2013. However, there is limited information available about public awareness on smog pollution in China, especially for where it concerns the residents living in villages. Based on a questionnaire survey, this study aims to help fill this gap. The results of the study show that the income of the majority of respondents comes from working in the city, accounting for $31.6 \%$ of the total income. The percentages for respondents related to access to smog information from various channels are as follows: TV $(28.5 \%)$, radio $(24.2 \%)$, neighbors $(13.5 \%)$, Internet $(9.8 \%)$, newspapers $(8.3 \%)$ and others $(7.8 \%)$. As for attitudes regarding the severity degree and main cause of smog pollution, most respondents (33.7\%) thought smog pollution in villages was somewhat severe, while $26.3 \%$ agreed that the main contributor to smog pollution was industrial emissions, followed by coal burning at power plants $(20.9 \%)$ and vehicle emissions $(17.7 \%)$. The results also indicate that most of the respondents were satisfied with the government's performance in terms of smog control. However, $67.9 \%$ of respondents indicated they would remain silent and not intervene when confronted by an activity that causes smog pollution. This study can help to improve an understanding of public awareness regarding smog pollution in China's rural areas and thereby activate positive public participation in smog pollution prevention and management in the search for sustainable development.
\end{abstract}

Keywords: smog; public awareness; public participation; pollution; energy; governance; China

\section{Introduction}

Since China established reforms and introduced its opening-up policy in 1978, the country has shown significant achievements in economic growth at a rate of $9.8 \%$. This phenomenon of economic progress is often referred to as the "Chinese miracle" [1]. However, economic growth in China encompasses high investment, high energy consumption and high pollutant emissions [2]. At present, China is confronting a lack of resources and limits to environmental capacity, which have become bottlenecks prohibiting sustainable development within both the society and economy, and which will cause long-term negative effects. Smog pollution is one of China's most pressing public health issues today and has received significant attention worldwide [3-5].

Smog is a type of air pollution with high atmospheric particulate matter (PM) concentrations. Waste gas from vehicles and industrial emissions during fuel combustion can react with sunlight in the atmosphere to form secondary pollutants. Primary emissions, together with the formed secondary 
pollutants, come into being, causing photochemical smog [6]. The China Meteorological Agency defines smog as a weather phenomenon with low atmospheric visibility of no more than $10 \mathrm{~km}$ at a relative humidity lower than $90 \%$, except in the presence of fog weather and dust storms [7]. In developing countries, smog severity is often aggravated by straw burning in neighboring agricultural areas. Stable weather conditions favor the formation of smog, while smog can also change the composition of aerosols through complex chemical reactions between aqueous and atmospheric phases [8]. Particulate matter in smog is usually highly toxic to humans and can cause severe illness, shorten lifespans and even lead to death [9]. Due to its evidently adverse impact on visibility, public health and even global climate, smog pollution has elicited significant global attention since the early 21 st century.

China experiences severe smog pollution problems [4]. The main composition of smog is sulphur dioxide $\left(\mathrm{SO}_{2}\right)$, nitrogen oxide $\left(\mathrm{NO}_{\mathrm{x}}\right)$ and particulate matter. $\mathrm{SO}_{2}$ and $\mathrm{NO}_{\mathrm{x}}$ are gaseous pollutants. It is widely accepted that particulate matter is the primary contributor to smog aggravation, since it can be combined with fog to form smog [10]. In China, the main reasons for the formation of smog include industrial emissions, vehicle exhaust, waste gas from coal burning, and dust from construction sites and road traffic.

On 4 June 2015, the Ministry of Environmental Protection of China officially issued the 2014 Chinese Environmental State Report. The report showed that only eight of the 74 monitored cities met urban air quality standards in 2014 in terms of annual average value, accounting for $10.8 \%$. In other words, $89.2 \%$ of the monitored cities experienced air pollution at a range of different levels. Figure 1 shows the annual average concentrations of $\mathrm{SO}_{2}, \mathrm{NO}_{2}, \mathrm{PM}_{10}, \mathrm{PM}_{2.5}, \mathrm{O}_{3}$ and $\mathrm{CO}$, as well as the percentages of cities that achieved the set air standards. Since $\mathrm{PM}_{10}$ (fine particles with a diameter of $10 \mu \mathrm{m}$ or less) and $\mathrm{PM}_{2.5}$ (fine particles with a diameter of $2.5 \mu \mathrm{m}$ or less) are the main pollutants that form smog, the low percentages of cities that reached the set standards indicate that smog pollution has clearly affected a wide range of areas and the impact of this is extremely serious. Along with the development of rural areas, villages in China are also experiencing worse smog pollution issues [5]. In addition, smog is not stationary and can flow into the countryside from cities. Thus, most rural areas cannot be exempted from smog pollution.
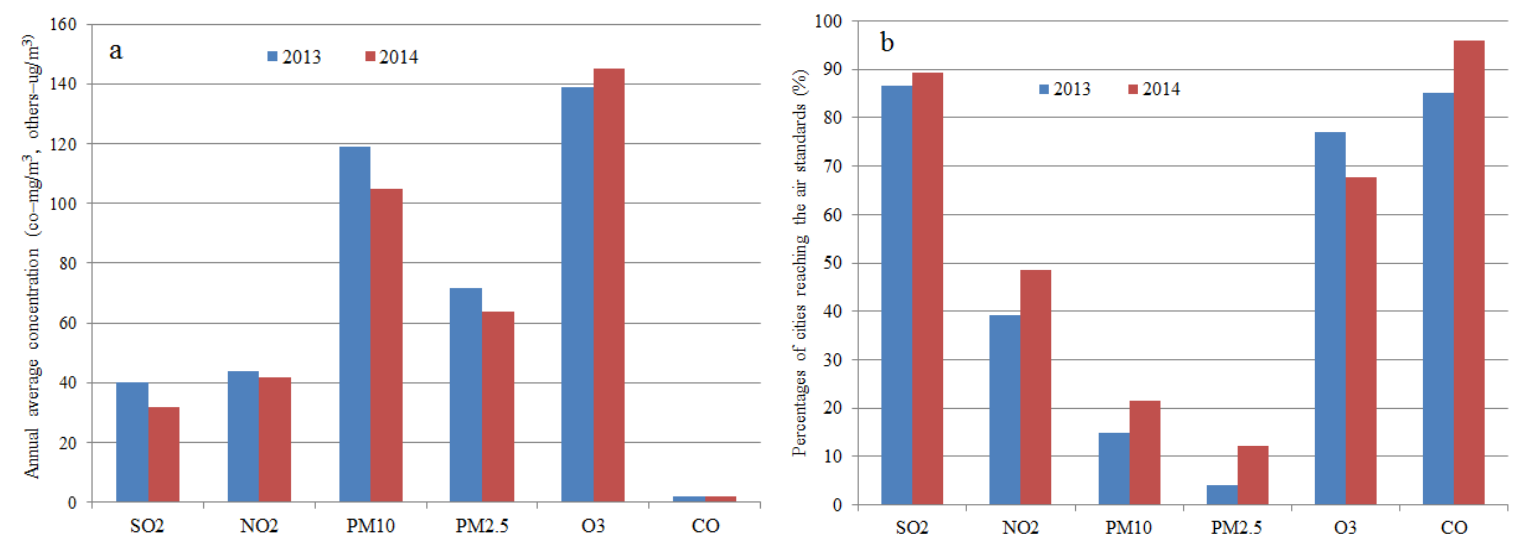

Figure 1. Annual average concentrations of pollutants (a) and the percentages of cities that achieved the set air standards (b). Data provided by the Ministry of Environmental Protection of China.

\section{Objective and Structure of This Study}

It is reported that most areas in China face serious smog pollution problems, especially since 2013. It will be interesting to discover how local residents respond to smog contamination issues. Some reports have already been received concerning the awareness among residents in Chinese cities about smog pollution. For example, Sun et al. [11] carried out face-to-face surveys and applied the contingent valuation method to estimate the public's willingness to pay for a reduction in air pollution within urban areas of China. However, we still do not know the level of awareness about smog 
pollution in China among residents living in villages. The current research is a survey study that applies a questionnaire, which was distributed in typical villages in central China. To the best of our knowledge, this is the first study to investigate the public's awareness of smog pollution among residents from rural areas in China. In the next section, a methodology for conducting the questionnaire survey is introduced (Section 2). Following that, several features of public awareness are presented and discussed including: options for rural residents to access smog information, their attitudes regarding the severity degree of smog in villages, their recognition regarding the primary cause of smog pollution, their satisfaction concerning the government's performance regarding smog control and their potential actions for intervening in an activity that causes smog pollution (Section 3). Finally, a summary of this study is presented (Section 4).

\section{Methods}

Xinjie rural areas with a population of 45,900 are located in central China $\left(113^{\circ} 02^{\prime}-113^{\circ} 19^{\prime} \mathrm{E}\right.$, $\left.31^{\circ} 26^{\prime}-31^{\circ} 86^{\prime} \mathrm{N}\right)$ and as a governance district are part of Suizhou City in Hubei Province. Flatland is the primary terrain in these areas. As such, these areas are also subject to being exposed to smog moving in from cities. One of the surveyors included in this study hails from this region, which facilitated conducting the questionnaire investigation in the area.

Xinjie rural areas include 16 villages in total. In this study, five villages were randomly chosen for conducting the questionnaire investigation. Respondents may have experienced some misunderstandings or miscommunications regarding the questionnaire, since their knowledge may have been insufficient due to poor nature of education within the countryside during the 20th century in China. Therefore, the surveyors explained the scenario and each item in the questionnaire to those who required an interpretation during completion of the survey.

In order to investigate public awareness of smog pollution in China's rural areas, the questionnaire form was organically composed of four parts. The first part disclosed demographic and economic information regarding respondents such as age, education and income. In the second part, valuation questions related to awareness were presented; in the third part, respondents' recognition regarding the government's performance of smog pollution control was surveyed. The fourth part addressed the potential for public participation in smog pollution prevention.

In this study, the basic sample size for the survey was determined using a confidence level of $90 \%$ with a confidence interval of 5\%. According to the Creative Research Systems [12], the following formulas were applied:

Basic sample size $(\mathrm{BSS})=\left[Z^{2} \times(p) \times(1-p)\right] / c^{2}$, where $Z=Z$ value $(1.64$ was used for $90 \%$ confidence level), $p=$ percentage picking a choice, expressed as decimal ( 0.5 was used for sample size needed), $c=$ confidence interval, expressed as decimal (0.05 was applied);

New sample size (NSS) on the basis of correction for finite population $=$ BSS $/[1+(B S S-1) /$ pop $]$, where pop $=$ population (45,900 was used). According to the calculations, BSS and NSS values were 269 and 268, respectively. Considering that some targeted people might not respond to the survey or some response might be invalid, 30 extra questionnaires were added. Thus, the final sample size was 298.

Questionnaires were randomly distributed using a simple random sampling method in December $2014 ; 251$ questionnaires were accordingly collected with a response rate of $84.2 \%$. However, 26 surveys were found to be invalid and as such, the validity rate of responses was $90.6 \%$. Hence, the analysis of this study was conducted based on the remaining 225 questionnaires.

The information collected via the questionnaire investigation was processed using SPSS 15.0 (IBM, Armonk, NY, USA) in order to establish the database and to carry out relevant analyses. Analysis of variance (ANOVA) was determined wherever applicable. Calculation was carefully performed and later, results were analyzed and discussed. 


\section{Results and Discussion}

\subsection{Basic Information of the Respondents}

The demographic composition of the respondents and the total population in the area is illustrated in Table 1. More respondents in the Xinjie rural areas were female (59.6\%), higher than the female composition in the total population (49.9\%). This may have been because, compared to women, more men choose to pursue work or do business in cities. Respondents aged over 55 accounted for $31.1 \%$, which was the highest proportion. This is in accordance with the phenomenon that persons aged between 20 and 50 in most villages in China generally choose to work in cities to earn a better income [13]. The respondents who had primary school education or who lacked any education made up the dominant portion of respondents, accounting for $38.2 \%$ of the total, while only $5.7 \%$ of respondents had vocational education, college or above-college experiences. For this reason, we needed to explain the scenarios to the group of people with a lower education level while conducting the survey. By comparison of age distribution between respondents and the total population, the samples randomly selected in this survey were representative.

Table 1. Basic information of the respondents and the total population, including gender, age and education level.

\begin{tabular}{|c|c|c|c|c|}
\hline Information & \multicolumn{2}{|c|}{ Numbers } & \multicolumn{2}{|c|}{ Percentage (\%) } \\
\hline \multicolumn{5}{|l|}{ Gender } \\
\hline Male & 91 & 22,980 & 40.4 & 50.1 \\
\hline Female & 134 & 22,920 & 59.6 & 49.9 \\
\hline $16-25$ & 25 & 5060 & 11.1 & 11.2 \\
\hline $26-35$ & 33 & 6859 & 14.7 & 14.9 \\
\hline $36-45$ & 44 & 8787 & 19.6 & 19.1 \\
\hline $46-55$ & 53 & 10,623 & 23.5 & 23.1 \\
\hline$>55$ & 70 & 14,571 & 31.1 & 31.7 \\
\hline High school & 54 & ND & 24.1 & ND \\
\hline Vocational school & 10 & ND & 4.4 & ND \\
\hline College and above & 3 & ND & 1.3 & ND \\
\hline
\end{tabular}

${ }^{a}$ Data obtained from a statistical yearbook from a local bureau; $\mathrm{ND}$ = data not provided.

\subsection{Income of the Respondents}

According to statistics, $26.7 \%$ and $25.3 \%$ of the respondents received an annual family income ranging from 10,000-15,000 and 5000-10,000 Chinese Yuan, respectively, contributing to the highest percentages of annual family incomes (Figure 2). A limited number of local residents had an annual family income of more than 20,000 Chinese Yuan. Overall, rural residents' incomes have increased due to the Chinese policy of abolishing rural taxation via rural taxation reform [14]. The primary income for the majority of respondents was from working in the city, accounting for $31.6 \%$ of the total incomes. Local employment $(27.1 \%)$ and farming $(21.3 \%)$ represented the second and third places for residents' income sources, respectively. With the development of urbanization, industrialization and modernization, more laborers are needed in cities, e.g., in the construction and service sectors [15]. Therefore, it is not surprising that the incomes of most families came from working in cities. There was a significant difference $(p<0.05)$ between family incomes and education levels among all of the respondents. 

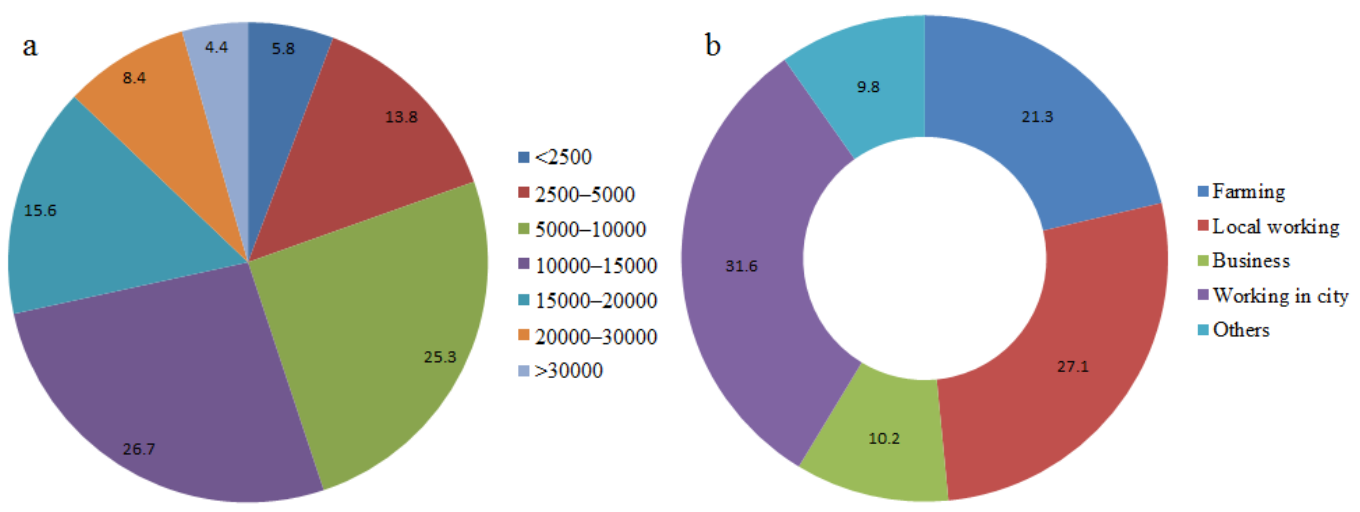

Figure 2. Annual family income (a) and the primary income sources (b) of respondents. Data given in percentage $(\%)$.

\subsection{Avenues for Accessing Smog Information}

A substantial proportion of residents ( $8 \%$ ) from the Xinjie rural areas had never heard of smog (Figure 3); most of them were older than 55 years and had a low education level. This is in line with research carried out by Dijkstra and Goedhart [16], who suggested that education level correlated with people's knowledge about certain topics. Most of the respondents accessed smog information from different channels. A majority of the respondents $(28.5 \%)$ accessed smog information from TV, followed by the radio $(24.2 \%)$ and neighbors $(13.5 \%)$. The percentages for TV and radio as smog information access channels were significantly $(p<0.05)$ higher than for other channels. In rural areas, almost every family has a TV and/or radio; it is therefore convenient for them gain smog information this way, for example from weather forecasts or news programs. A small proportion of the respondents $(9.8 \%)$ could access the Internet using a computer or smart phone, where they were able to read news or reports online. It is not surprising to see that $90 \%$ of respondents from this proportion are aged less than 45 . The findings also show that $8.3 \%$ and $7.8 \%$ of local people suggested that smog information was available to them via newspapers or other channels, respectively.

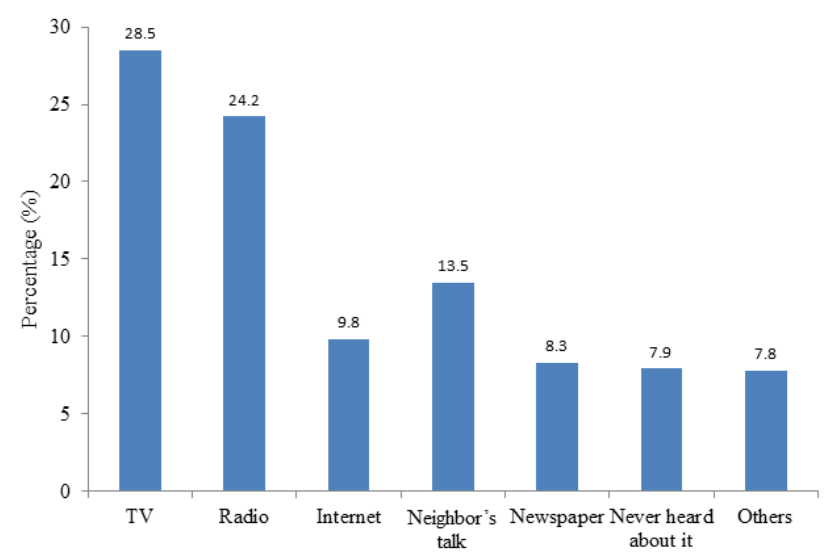

Figure 3. The ways for respondents to access smog information.

The access available to smog information channels in rural areas is not always in agreement with those available in cities, where most people have access to a range of electronic devices such as smart phones and tablets. Therefore, residents from urban areas have more convenient access to smog information through media channels such as social networks and/or blogs $[17,18]$. In an effort to make smog information more available and people's recognition of smog more comprehensive, more needs to be done including more propaganda activities from the government at all levels, and non-governmental organizations (NGOs), universities, industries and communities should be 
encouraged to participate in disseminating this information. Rural residents can, in this way, develop a better understanding of the issue and become involved in environmental pollution prevention through active public participation.

\subsection{Attitudes on the Severity Degree of Smog Pollution in Villages}

People's attitudes on whether smog pollution in villages is severe were mainly based on perceptual knowledge and subjective judgments or feelings. Additionally, people living in different areas may have different levels of awareness about this issue, since logical thinking or extrapolation was not required during the investigation.

Most of the respondents thought that smog pollution in villages was somewhat severe, accounting for $33.7 \%$ of the total respondents (Figure 4). In contrast, $26.1 \%$ and $20.4 \%$ of residents agreed that smog pollution in villages was severe and very severe, respectively. The findings in this study contrasted those achieved by Wang et al. [18], who carried out a survey in Zibo City and suggested a majority of respondents $(60.2 \%)$ recognized that smog pollution was very serious. Compared to city residents, who constantly receive information or alerts about severe air pollution via the media, rural residents were much less aware of smog pollution. For example, $13.5 \%$ of respondents denied any smog pollution and $6.3 \%$ did not know whether smog pollution was severe or not. This may have been because they had little knowledge about smog; additionally, it is also easy for them to mistake smog for natural fog. In addition, in Chinese rural areas, farmers care more about factors such as income and food and show less concern for the environment. Research by Lawson et al. [19] suggests that the economic level in a region correlates with the environmental awareness and concerns of the local people. However, with the development of rural areas, environmental issues will inevitably receive growing attention.

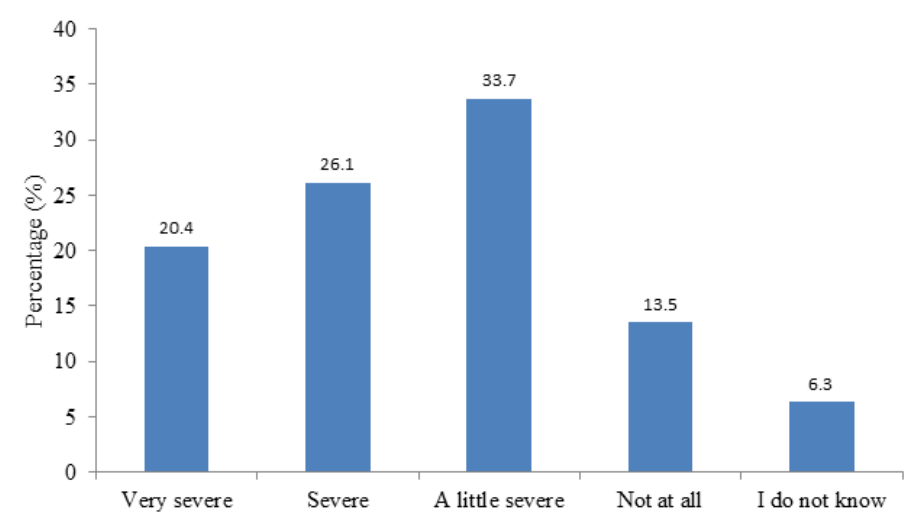

Figure 4. Respondents' attitudes regarding the severity degree of smog pollution in villages.

\subsection{Recognition Regarding the Main Cause of Smog Pollution}

The survey results showed that most of the respondents realized that anthropogenic activities are to be blamed for smog pollution (Figure 5); $26.3 \%$ of residents thought the main contributor to smog pollution lay in industrial emissions, followed by coal burning at power plants $(20.9 \%)$ and vehicle emissions (17.7\%). This is partially in accordance with results achieved by Wang et al. [18], who conducted a similar survey within a city and found three major recognized causes, in the following order: industrial emissions, vehicle emissions and coal burning at power plants. Straw burning in the field was believed to be the main cause of smog pollution by $8.3 \%$ of respondents. In China, it is very common for farmers to burn straw in fields or on-site, since they view burning as the easiest way to dispose of agricultural waste. However, during our survey we discovered that most farmers, especially those with lower education levels, did not recognize that straw burning can contribute to environmental pollution. Straw burning can generate a range of air contaminants such as particulate matter, organic carbon, elemental carbon and 32 polycyclic aromatic hydrocarbons [20]. Most of the individuals surveyed in this case study complained that leaving straw on farmland would affect the 
growth of the next season's crops. Thus, air pollution control from straw burning in China calls for efficient recycling, i.e., its return into soil as fertilizer or application in biogas production via anaerobic digestion [21].

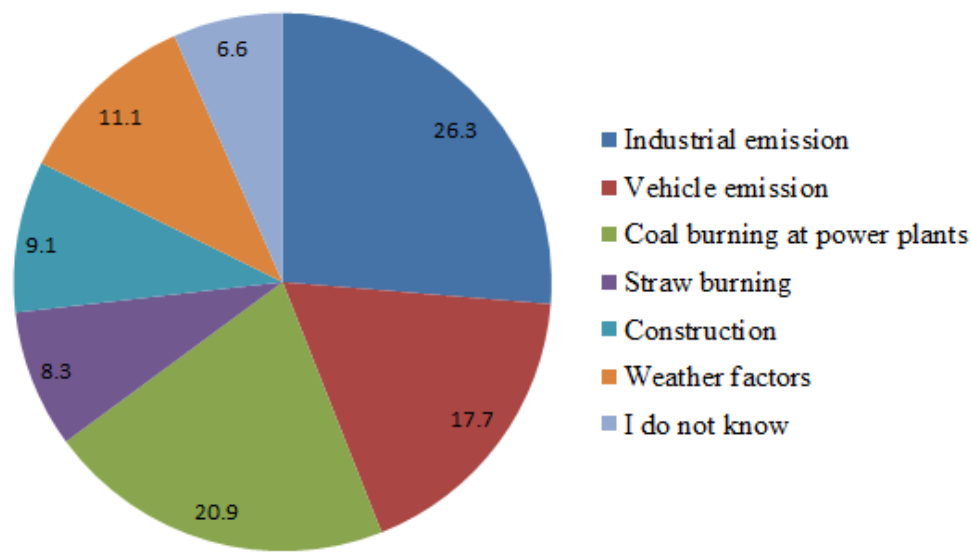

Figure 5. Recognition regarding the main cause of smog pollution. Data in percentage (\%).

In addition, in recent years, ever more construction has occurred in rural areas, resulting in significant concentrations of flying dust and ash. In this context, $9.1 \%$ of the respondents believed construction to be a primary contributor to smog generation. Furthermore, a substantial number of local people $(11.1 \%)$ attributed the formation of smog primarily to weather factors, since it is widely recognized that special weather conditions (e.g., the winter period) favor smog formulation [22].

\subsection{Satisfaction Concerning the Government's Performance in the Area of Smog Control}

It appears that most of the respondents were satisfied with the government's performance related to smog control: $18.7 \%$ were "very satisfied", $38.9 \%$ were "satisfied" and $28.6 \%$ were "somewhat satisfied" (Figure 6). In contrast, only 11.5\% of those surveyed chose the "not at all" satisfied option ( $88.5 \%$ of the respondents from this proportion had higher education levels, e.g., vocational school and college), indicating that they were unhappy with the government's response on this issue.

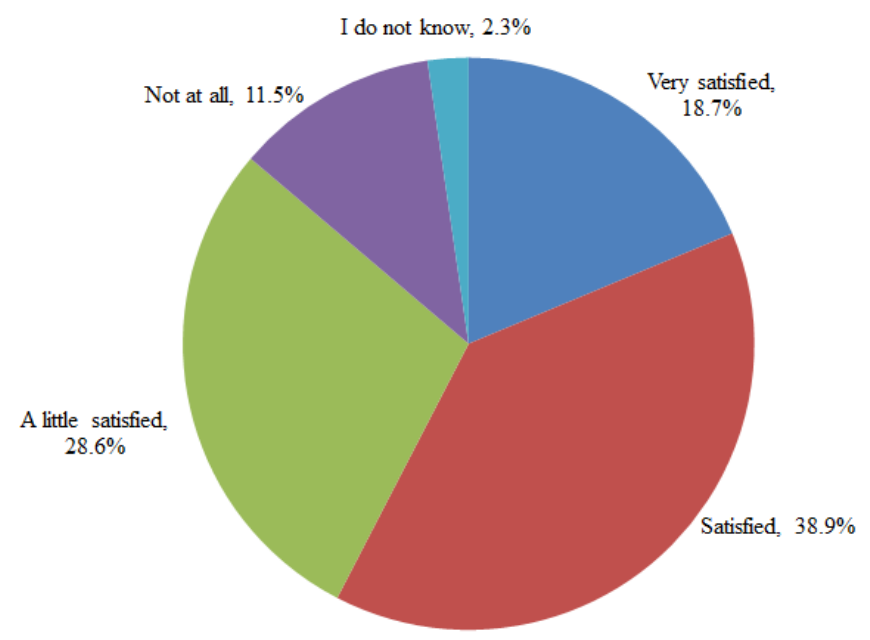

Figure 6. Satisfaction concerning the government's performance in the area of smog control.

The percentage data pertaining to satisfaction concerning the government's performance in the area of smog control were extremely high. Zheng and Li [23] implemented a survey measuring public satisfaction with the government regarding environmental protection in Guangzhou City and found a 
low satisfaction rate. The high satisfaction percentage in the present study was partially due to the fact that most residents did not think smog pollution was serious (Figure 4). Particularly in rural areas, farmers have less access to smog information. Therefore, an alert about the danger of smog and how to take preventive measures should be provided to rural residents. Another reason for the high satisfaction percentage in the present study is that the government has also begun disseminating measures or activities in coding with smog problems. Thus, local residents are inclined to be confident about the government's efforts in this area.

\subsection{Potential Action for Intervention in an Activity Causing Smog Pollution}

In terms of respondents' potential action for intervening in an activity that causes smog pollution, different opinions were measured among the respondents. A predominant percentage of respondents $(67.9 \%)$ chose to remain silent without any intervention, despite not liking behaviors that led to smog pollution (Figure 7). These respondents may instead passively wait for environmentally conscious individuals to act on their behalf [24]. Only $17.7 \%$ of the surveyed people wanted to be involved in interventions. A limited number of respondents (14.4\%) did not care about smog-causing activities. This may have been because they were unaware of the relevant harmfulness of smog pollution, or because they thought intervention was not their business, which is a common psychological phenomenon [18]. There was a significant $(p<0.05)$ positive relationship between respondents' intervention choices and their education levels. People with slightly higher education levels (e.g., high school, vocational school and college) were more prone to protecting the environment and becoming involved in fighting smog pollution. In addition, more male respondents chose to be involved in interventions, accounting for $68.1 \%$. Thus, public education targeting rural residents with lower education levels should be improved.

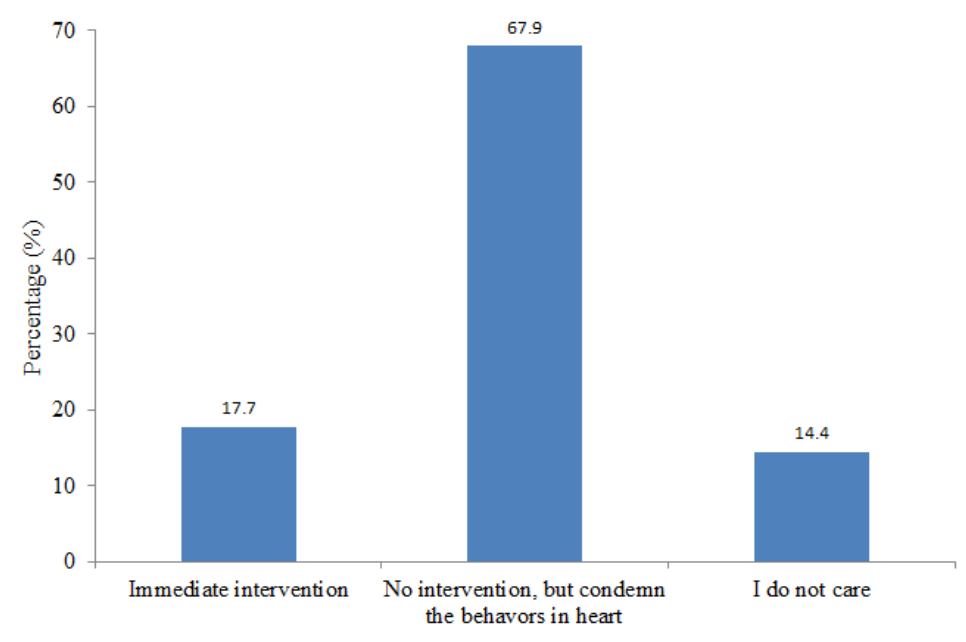

Figure 7. Potential action regarding intervention in an activity that causes smog pollution.

Potential intervention in an activity that causes smog pollution reflects, to some extent, public participation. To fight against environmental pollution, local public participation is a precondition for long-term sustainable development and positive attitudes are the driving force for doing so [25]. During law and regulation formulation, the public's opinions must be taken into account. The government must positively encourage the public to participate in smog control activities. Channels that facilitate the public reporting any pollution-causing activities must be available and public, and concerns and claims must be responded to in a timely manner, with the relative appropriate actions taken into effect. Only in this way can the public's motivation and enthusiasm for engagement in environmental protection be promoted. 


\section{Conclusions}

The present study discloses public awareness on smog pollution in China's rural areas. The demographic results show that the dominant portion of respondents was from the group of those people aged over 55, accounting for $31.1 \%$, while the respondents who had primary school education or who lacked any education made up the highest proportion of respondents, accounting for $38.2 \%$ of the total. The primary income for the majority of respondents was from working in the city $(31.6 \%)$, while local employment $(27.1 \%)$ and farming $(21.3 \%)$ represented the second and third places for residents' income sources, respectively. The findings show that TV and radio were the main channels for respondents with which to access smog information. Most of the respondents $(33.7 \%)$ thought that smog pollution in villages was somewhat severe; $26.3 \%, 20.9 \%$ and $17.7 \%$ of respondents suggested that the main contributors to smog pollution were industrial emissions, coal burning at power plants and vehicle emissions, respectively. More than $82 \%$ of the surveyed individuals expressed satisfaction with the government's performance regarding smog control. In contrast, an extremely high proportion of respondents $(67.9 \%)$ would not intervene in a range of activities that cause smog pollution, despite condemning these behaviors. This study also suggests that environmental education among the public can have an important role to play in preventing smog, since it can facilitate positive public participation in smog pollution prevention. The knowledge provided by this paper can help to improve an understanding of public awareness regarding smog pollution, contributing to coping with the smog crisis, especially from a public participation perspective. The findings from this survey can be applied by other researchers and policy-makers worldwide for promoting smog prevention policies in smog-stricken countries or regions.

Acknowledgments: This work benefited from the start-up project "Research on Theory and Practice of Ecological Civilization in China", funded by the Independence Sci-Tech Innovation Foundation of the Huazhong Agricultural University (No. 2662016QD050). This work also partially benefited from the support of the Kone Foundation project in Finland. The authors would like to thank the rural residents who participated in the survey. The authors would also like to thank the two anonymous reviewers for their helpful comments and suggestions which greatly improved the manuscript.

Author Contributions: Li Jiang and Liandong Zhu designed and conducted the study and wrote this draft. Xianglin He and Erkki Hiltunen provided some important guidance in survey design and data analysis.

Conflicts of Interest: The authors declare no conflict of interest.

\section{References}

1. Golley, J.; Wei, Z. Population dynamics and economic growth in China. China Econ. Rev. 2015, 35, 15-32. [CrossRef]

2. Zhu, L.; Hiltunen, E.; Antila, E.; Huang, F.; Song, L. Investigation of China's bio-energy industry development modes based on SWOT-PEST model. Int. J. Sustain. Energy 2015, 34, 552-559. [CrossRef]

3. Slezak, M. China plans to create artificial rain to combat smog. New Sci. 2013, 220, 7. [CrossRef]

4. Li, J.; Lu, K.; Lv, W.; Li, J.; Zhong, L.; Ou, Y.; Chen, D.; Huang, X.; Zhang, Y. Fast increasing of surface ozone concentrations in Pearl River Delta characterized by a regional air quality monitoring network during 2006-2011. J. Environ. Sci. 2014, 26, 23-36. [CrossRef]

5. Zhou, M.; He, G.; Fan, M.; Wang, Z.; Liu, Y.; Ma, J.; Ma, Z.; Liu, J.; Liu, Y.; Wang, L.; et al. Smog episodes, fine particulate pollution and mortality in China. Environ. Res. 2015, 136, 396-404. [CrossRef] [PubMed]

6. Aidaoui, L.; Triantafyllou, A.G.; Azzi, A.; Garas, S.K.; Matthaios, V.N. Elevated stacks' pollutants' dispersion and its contributions to photochemical smog formation in a heavily industrialized area. Air Qual. Atmos. Health 2015, 8, 213-227. [CrossRef]

7. Gao, J.; Tian, H.; Cheng, K.; Lu, L.; Zheng, M.; Wang, S.; Hao, J.; Wang, K.; Hua, S.; Zhu, C.; et al. The variation of chemical characteristics of $\mathrm{PM}_{2.5}$ and $\mathrm{PM}_{10}$ and formation causes during two haze pollution events in urban Beijing, China. Atmos. Environ. 2015, 107, 1-8. [CrossRef]

8. Tan, J.H.; Duan, J.C.; He, K.B.; Ma, Y.L.; Duan, F.K.; Chen, Y.; Fu, J.M. Chemical characteristics of PM $_{2.5}$ during a typical haze episode in Guangzhou. J. Environ. Sci. 2009, 21, 774-781. [CrossRef] 
9. Chen, R.; Zhao, Z.; Kan, H. Heavy smog and hospital visits in Beijing, China. Am. J. Respir. Crit. Care Med. 2013, 188, 1170-1171. [CrossRef] [PubMed]

10. Yuan, Y.; Liu, S.; Castro, R.; Pan, X. PM 2.5 monitoring and mitigation in the cities of China. Environ. Sci. Technol. 2012, 46, 3627-3628. [CrossRef] [PubMed]

11. Sun, C.; Yuan, $\mathrm{X} . ; \mathrm{Xu}, \mathrm{M}$. The public perceptions and willingness to pay: From the perspective of the smog crisis in China. J. Clean. Prod. 2016, 112, 1635-1644. [CrossRef]

12. Creative Research Systems. Available online: http://www.surveysystem.com (accessed on 29 October 2016).

13. Long, H.; Li, Y.; Liu, Y.; Woods, M.; Zou, J. Accelerated restructuring in rural China fueled by 'increasing vs. decreasing balance' land-use policy for dealing with hollowed villages. Land Use Policy 2012, 29, 11-22. [CrossRef]

14. Xu, C.; Wang, H.H.; Shi, Q. Farmers' income and production responses to rural taxation Reform in three regions in China. J. Agric. Econ. 2012, 63, 291-309. [CrossRef]

15. Buhaug, H.; Urdal, H. An urbanization bomb? Population growth and social disorder in cities. Glob. Environ. Chang. 2013, 23, 1-10. [CrossRef]

16. Dijkstra, E.M.; Goedhart, M.J. Development and validation of the ACSI: Measuring students' science attitudes, pro-environmental behaviour, climate change attitudes and knowledge. Environ. Educ. Res. 2012, 18, 733-749. [CrossRef]

17. Zhou, L.; Wang, T. Social media: A new vehicle for city marketing in China. Cities 2014, 37, 27-32. [CrossRef]

18. Wang, Y.; Sun, M.; Yang, X.; Yuan, X. Public awareness and willingness to pay for tackling smog pollution in China: A case study. J. Clean. Prod. 2016, 112, 1627-1634. [CrossRef]

19. Lawson, E.T.; Gordon, C.; Schluchter, W. The dynamics of poverty-environment linkages in the coastal zone of Ghana. Ocean Coast. Manag. 2012, 67, 30-38. [CrossRef]

20. Wei, S.; Shen, G.; Zhang, Y.; Xue, M.; Xie, H.; Lin, P.; Chen, Y.; Wang, X.; Tao, S. Field measurement on the emissions of PM, OC, EC and PAHs from indoor crop straw burning in rural China. Environ. Pollut. 2014, 184, 18-24. [CrossRef] [PubMed]

21. Zhu, L. The combined production of ethanol and biogas from microalgal residuals to sustain microalgal biodiesel: A theoretical evaluation. Biofuels Bioprod. Biorefin. 2014, 8, 7-15. [CrossRef]

22. Mohammadi, H.; Cohen, D.; Babazadeh, M.; Rokni, L. The effects of atmospheric processes on Tehran smog forming. Iran. J. Public Health 2012, 41, 1-12. [PubMed]

23. Zheng, F.; Li, Y. Economic development, social equity and environmental protection: Based on the view of governments' performance-Take Guangzhou from 2008 to 2010 as an example. J. Public Manag. 2013, 1, 1-5.

24. Li, W.; Liu, J.; Li, D. Getting their voices heard: Three cases of public participation in environmental protection in China. J. Environ. Manag. 2012, 98, 65-72. [CrossRef] [PubMed]

25. Kolahi, M.; Moriya, K.; Sakai, T.; Khosrojerdi, E.; Etemad, V. Introduction of participatory conservation in Iran: Case study of the rural communities' perspectives in Khojir National Park. Int. J. Environ. Res. 2014, 8, 913-930.

(C) 2016 by the authors; licensee MDPI, Basel, Switzerland. This article is an open access article distributed under the terms and conditions of the Creative Commons Attribution (CC-BY) license (http://creativecommons.org/licenses/by/4.0/). 